\title{
The Comparison of Three Major Occupations for User Acceptance of Information Technology: Applying the UTAUT Model
}

\author{
Yu-Shan Cheng*, Tsai-Fang Yu, Chin-Feng Huang, Chien Yu, Chin-Cheh Yu \\ Department of Applied Technology and Human Resource Development, National Taiwan Normal University, Taipei, China. \\ Email: high2468@gmail.com
}

Receive January $22^{\text {nd }}, 2011$; revised April $3^{\text {rd }}, 2011$; accepted April $13^{\text {th }}, 2011$

\begin{abstract}
This study investigated whether the differences of gender, age, and occupation for m-learning showed significance on the utilization of the mobile devices and to figure out if the variation may influence the performance expectancy, effort expectancy and the social influence to the behavioral intention or even to the behavior of usage. When the employees' behavioral intention was low, the director of managers or HR department can suggest the employees' colleagues, superior manager or friends to communicate with them to enhance their behavioral intention and to use it. And it suggested that male employees and elder employees should be put more emphasis on the communication to enhance their behavioral intention. UTAUT model with different kinds of businesses for m-learning but the conclusion did not investigate the differences of the adoption of the mobile devices in each industry. Basing on this, this study attempted to investigate whether the difference occupations showed significance on the utilization of the mobile devices.
\end{abstract}

Keywords: Unified Theory of Acceptance and Use of Technology (UTAUT), Manufacturing, Service, Bank

\section{Introduction}

Because m-learning (mobile learning) industry played the role as the index of the development of knowledge economy and digital economy and that it was also a high value added industry which was the important base of improving total competitive strength of the occupations in a country, countries around the world have investigated a lot of resources to promote the m-learning industry. Therefore, m-learning industry has not been an industry issue in any country, but also the key to whether the companies of the same business can have the advantage across nations under the frame of knowledge economy.

The adoption of information and communication technology (ICT) can improve the learning when giving a learner-centered lecture [1]. Therefore, triggered by the marketing competition, service improvement and working performance, an organization would investigate a lot of the information technology and apply it to the education of the employees to deduce the training cost and increase the learning will of the employees to improve their performance, widen the training domain and shorten the learning curve. etc. [2,3].
In 2007, the ratios among the occupations of manufacture, banking and service in buying or making e-learning platform was $12.4 \%, 37.1 \%, 14.3 \%$ respectively, while the ratios went up to $16.7 \%, 54.3 \%$ and $25.7 \%$ in 2008 which showed a fair development [4]. In order to figure out current situation of the three major occupations in Taiwan with m-learning when giving employees training, the study adopted the UTAUT model which was proposed by as in [5] to investigate the issue. They used eight models to study the problems and found out that the expected validity would have significant improved after adding adjustment variables to six of the eight models. Reference [5] adopted four different kinds of corporations to test the model, namely the product development department of the entertainment business, the marketing department of the information service business, the business account management of the banking business and the account department of the public-operated business. Understanding that as in [5] established UTAUT model with different kinds of businesses but the conclusion did not investigate the differences of the adoption of the mobile devices in each industry. Despite that as in [6] investigated the demonstration and 
found out that the modulators of the technology acceptance model of the current users stood the significant influences [7]. Basing on this, the study attempted to investigate whether the differences of gender, age, and occupation showed significance on the utilization of the mobile devices and to figure out if the variation may influence the performance expectancy, effort expectancy and the social influence to the behavioral intention or even to the behavior of usage. Finally, this study showed some recommendations for future training are issued.

\section{Unified Theory of Acceptance and Use of Technology}

Technology adoption research has flourished in recent years [6-13].

Many researchers have made significant efforts in building theories to examine and predict the determinants of user technology acceptance $[9,14,15]$.

Existing models of ICT acceptance have their foundations in several diverse theories, most noticeably the innovation diffusion theory, where individuals' perceptions about using an innovation are considered to affect their adoption behavior $[14,15]$.

Some theoretical models that attempted to explain the relationship between user beliefs, attitudes, intentions and actual system use include Theory of Reasoned Action (TRA) [16,17], Theory of Planned Behavior (TPB) [18] and Technology Acceptance Model (TAM) [8].

TAM was rooted in the TRA, a model concerned with determinants of consciously intended behaviors $[4,16,17]$. TRA proposed that beliefs influence attitudes, which in turn lead to intentions and then consequently generate behaviors. Adopting TRA in the context of user technology acceptance, TAM assumed that beliefs about usefulness and ease of use were the primary determinants of user technology adaptation. Prior study has noted the similarity between perceived usefulness and ease of use beliefs in TAM and the relative advantage and complexity constructs in diffusion theory $[5,11,14,19]$.

TAM has received extensive empirical support through validations, applications and replications for its power to predict use of information technology $[5,8,11$, 14,20].

Perceived usefulness was the degree to which a person believed that using a particular system would enhance his or her job performance, and perceived ease of use is the degree to which a person believes that using a particular system will be free of effort [8].

Attitude toward adoption has been found to play a key role in technology acceptance within the consumer context [10].

Deservedly, researchers have examined the acceptance of technology, and several models have been proposed in the literature. These models include the Technology Acceptance Model (TAM) [8], and its extension (TAM2) [21], and models based on the Theory of Reasoned Action [22], Innovation Diffusion Theory [19], Triandis model [23], Motivation [24], Theory of Planned Behavior [11], Social Cognitive Theory [25,26], and, recently, the Unified Theory of Acceptance and Use of Technology (UTAUT) [5]. Each model would have the same dependent variable, usage, but used various antecedents to understand acceptance of technology [27,28].

Based on eight prominent models in the field of IT acceptance research, as in [5] proposed a unified model, called the unified theory of acceptance and used of technology (UTAUT), which integrates element across the eight models. The eight models consist of Theory of Reasoned Action (TRA) [17], Technology Acceptance Model (TAM) [8], Motivational Model (MM) [24], Theory of Planned Behavior (TPB) [29], the Combined TAM and TPB (C-TAM-TPB) [30], Model of PC Utilization (MPCU) [23,31], Innovation Diffusion Theory (IDT) $[19,32]$ and Social Cognitive Theory (SCT) $[25,33]$. Based on the study of reference [5], briefly reviewed the core constructs in each of the eight models, which have been theorized as the determinants of IT behavioral intention and/or behavior [28].

Various alternative approaches have used in analyzing consumers' acceptance of new technologies [8,34,35]. One of the more recent theories, the unified theory of acceptance and use of technology (UTAUT) (see Figure 1) by as in [5] provided a comprehensive framework for technology adoption analysis. The model was formulated based on conceptual and empirical similarities across eight technology acceptance models. UTAUT contains four core determinants of behavioral intention-performance expectancy, effort expectancy, social influence and facilitating conditions [5]. Although the UTAUT model is relatively new, it has inspired researchers to try its suitability in different contexts [36]. One of the strengths of the UTAUT model is that it considers the role of several moderating variables, namely gender, age, experience and voluntariness of use [5]. These moderators are assumed to influence the significance of the four core determinants [36].

The UTAUT aims to explain users' behavioral intention to use an information system and their subsequent usage behavior. The theory holds that four key constructs (performance expectancy, effort expectancy, social influence, and facilitating conditions) were direct determinants of behavioral intention and behavior [5]. But as in [5] consider that when both performance expectancy constructs and effort expectancy constructs are present, 
facilitating conditions becomes non-significant in predicting intention.

The variables of gender, age, experience, and voluntariness of use are posited to moderate the impact of the four key constructs on behavioral intention and behavior [5]. These determinants and moderators will be used to extend the proposed research model.

\section{Research Model and Hypotheses}

The study model tested in this study was shown in Figure 2. In this model, performance expectancy (PE), effort expectancy (EE) and social influence (SI) were hypothesized to be determinants of behavioral intention (BI) to use m-learning system. We also hypothesized that gender, age and occupation differences would moderate the influence of these determinants on behavioral intention and usage. The reason why this study did not discuss Facilitating conditions was because as in [5] considered that when both performance expectancy constructs and effort expectancy constructs were present, facilitating conditions becomes non-significant in predicting inten- tion. The proposed constructs and hypotheses were supported by previous literature. The following sections elaborated on the theory base and derive the hypotheses.

\subsection{Performance Expectancy}

Reference [5] defined performance expectancy as the extent to which an individual believes that using an information system help him or her to attain benefits in job performance. Performance expectancy has been justified as a predictor of behavioral intention to use IT [5]. Performance expectancy consisted of Perceived Usefulness [8,22], Extrinsic Motivation [24], Job-fit [23], Relative Advantage [19], and Outcome Expectations [25,26].

Prior studies suggested that performance expectancy was significant in shaping an individual's intention to use new technology, and base on the UTAUT and previous literature (e.g., $[1,5,21])$. This study expected that performance expectancy was a significant determinant of behavioral intention to use m-learning. Thus, the following hypothesis was tested:

Hypothesis 1: Performance expectancy has a positive

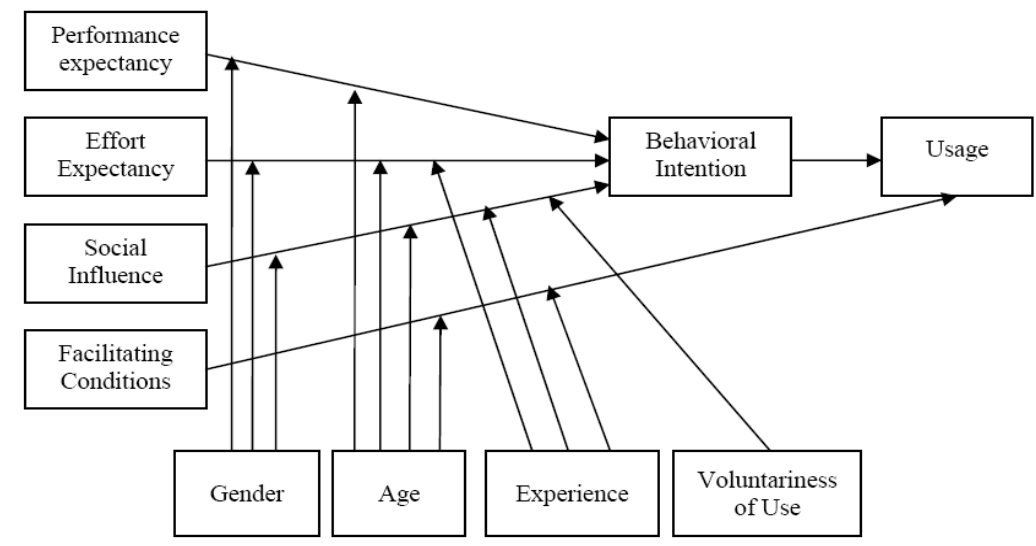

Figure 1. The UTAUT model. Source: Reference [5].

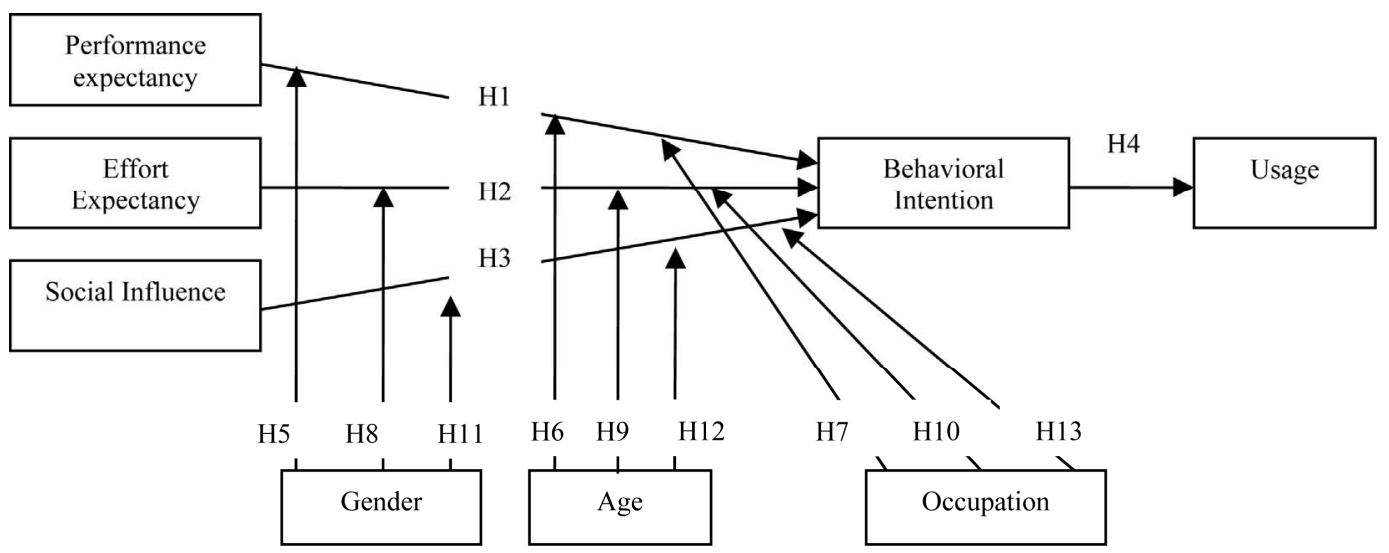

Figure 2. Conceptual framework and hypotheses. 
effect on behavioral intention to use m-learning.

\subsection{Effort Expectancy}

Reference [5] defined effort expectancy as the degree of ease associated with the use of the information system. The three constructs from the different models that related to effort expectancy are perceived ease of use (TAM/ TAM2), complexity (MPCU) and ease of use (IDT) [5]. Effort Expectancy consisted of Perceived Ease of Use [8,22], Complexity [23], and Ease of Use [19].

Prior studies suggest that effort expectancy was significant in shaping an individual's behavioral intention to use new technology, and base on the UTAUT and previous literature (e.g., $[1,5,21,36])$. This study expected that effort expectancy was a significant determinant of behavioral intention to use m-learning. Thus, the following hypothesis is tested:

Hypothesis 2: Effort expectancy has a positive effect on behavioral intention to use m-learning.

\subsection{Social Influence}

Venkatesh et al. [5] defined social influence as the extent to which a person perceives that important others believe he or she should use a new information system. Three constructs from the existing models captured the concept of social influence: subjective norm (TRA, TAM2, TPB and C-TAM-TPB), social factors (MPCU) and image (IDT) [5].

Social Influence consisted of Subjective Norm [11, 17,22,29,30], Social Factors [23], and Image [19].

Prior studies suggested that social influence was significant in shaping an individual's intention to use new technology $[19,21,23]$. Based on the UTAUT and previous literature (e.g., [5,12,36]). We expected that social influence was a significant determinant of behavioral intention to use m-learning. Thus, the following hypothesis was tested:

Hypothesis 3: Social influence has a positive effect on behavioral intention to use m-learning.

\subsection{Behavioral Intention}

Consistent with the underlying theory for all of the intention models discussed in this paper, we expected that behavioral intention would have a significant positive influence on technology usage [5].

Hypothesis 4: Behavioral intention has a significant positive influence on usage.

\subsection{Moderator Effects}

Based on the UTAUT and previous literature [12], gender and age were theorized to play a moderating role on the influence of performance expectancy on behavioral intention. That was, the influence of performance expectancy on behavioral intention would be moderated by gender and age, such that the effect would be stronger for men and particularly for younger men [5].

From prior studies suggested performance expectancy was significant in behavioral intention, and manufacturing, service, and banking occupations may be affected (e.g., $[1,37,38])$.Therefore, this study tested the following hypotheses:

Hypothesis 5: Performance expectancy influences behavioral intention to use m-learning more strongly for men than for women.

Hypothesis 6: Performance expectancy influences behavioral intention to use m-learning more strongly for younger than for older people.

Hypothesis 7: Performance expectancy influences behavioral to use m-learning intention relationship would be the impact of different occupations.

Prior studies suggested that constructs associated with effort expectancy would be stronger determinants of individuals' intention for women [12,39] and for older workers [12]. The influence of effort expectancy on behavioral intention would be moderated by gender and age, such that the effect would be stronger for women, particularly for older women [5]. Thus, this study tested the following hypotheses:

Hypothesis 8: Effort expectancy influences behavioral intention to use m-learning more strongly for women than for men.

Hypothesis 9: Effort expectancy influences behavioral intention to use m-learning more strongly for older than for younger people.

From prior studies suggested performance expectancy was significant in behavioral intention, and manufacturing, service, and banking occupations might be affected (e.g., $[1,6,37])$. Thus, the following hypothesis was tested:

Hypothesis 10: Effort expectancy influences behavioral intention to use m-learning relationship would be the impact of different occupations.

This study incorporated social influence to the study model in order to explore the moderating effect of age and gender differences on the relationships between social influence and behavioral intention. The effect of social influence on behavioral intention would be moderated by gender and age, such that the effect would be stronger for women, particularly older women. Thus, the following hypotheses were tested:

Hypothesis 11: Social influence influences behavioral intention to use m-learning more strongly for women than for men.

Hypothesis 12: Social influence influences behavioral intention to use m-learning more strongly for older than 
for younger people.

From prior studies suggested performance expectancy was significant in behavioral intention, and manufacturing, service, and banking occupations might be affected (e.g., $[1,37,38])$. Thus, the following hypothesis was tested:

Hypothesis 13: Social influence influences behavioral intention to use m-learning relationship would be the impact of different occupations.

\subsection{Measures}

This study adopted SPSS18.0 and LISREL 8.53 statistics software to study the hypothesis test and data analysis. The statistic method adopted in this study includes descriptive statistical analysis, common method variance, reliability analysis, confirmatory factors analysis, and correlation analysis. Then, this study adopted a structural equation model to analyze the relation among the variables in the model and interpret the study model and hypothesizes.

\section{Methodology}

\subsection{Data Collection and Sample Characteristics}

Taiwan Common Wealth Magazine would make lists for manufacture business, service business and banking business with the standards of revenue, total assets, after-tax net profit, stock holders' equity, capital, profitability, return on assets, return on equity, debt ratio, the number of employees, and employee output. Basing on the standards, the magazine listed the top 1000 companies of manufacture business, top 500 companies of the service business and top 100 companies in banking business.

The research objects in the study were the top 1600 enterprises in Taiwan. The questionnaires were delivered with the method of general survey. The collected data from 2009, October 1st to November 31st were used for cross-sectional study. There were 350 questionnaires collected with the recovery rate of $21.875 \%$. After removing the invalid questionnaires with obvious contradiction, there were 264 valid questionnaires collected with the recovery rate of $16.5 \%$. Among the valid questionnaires, 143 belong to manufacture business, 89 belong to service business and 32 belong to banking business.

The repliers of the research were the managers of the department of internal training which includes management department, human resources department and information sections. In the 264 valid questionnaires, female repliers took the majority $(\mathrm{N}=165 ; 62.5 \%)$. Most of the informants fall between 31 to 35 years old $(\mathrm{N}=74$;
$28.1 \%)$, then 26 to 30 years old $(\mathrm{N}=63 ; 23.9 \%)$.

\subsection{Common Method Variance}

When giving test at the same time point with the self report inventory and a single source informant, the problem of common method variance (CMV) was easily observed when the questions were similar with each other and the semantics was positive [40]. This study took the Harman's one-factor test which was the most used test for common method variance to testy the severity of the common method variance problem: 1) Each question is evaluated with exploratory factor analysis to test the results of all non-shift factor analysis. If there are more than two factors in the analysis or less than $50 \%$ of the explained variance, then the effected level of the common method variance is not critical; 2) Then, all questions are put together to go through the single-factor confirmatory factor analysis. If the result shows that not all the questions have more than 0.50 of the burden level or poor verify model, then the effected level of the common method variance is not critical.

This study extracted three factors with the questions analyzed with exploratory factor analysis. The result showed that the sample data of the research did not have the problem of severe common method variance. The single-factor confirmatory factor analysis also indicated that it was not the case that all questions were beyond the burden level of 50. In the model test result, the value of $\chi^{2}$ was 1196.53 , with the freedom level set as 77 and the significance test ratio probability value p-value as .000 which is significant. Besides, other fit index value showed: GFI $=0.61$, AGFI $=0.46, \mathrm{NFI}=0.81$, NNFI $=$ $0.78, \mathrm{CFI}=0.82$, that was more than .90 below the fit standard while the RMSEA is 0.235 which is more than 0.05 . All of these values showed that the single-factor confirmatory factor analysis has indicated poor fit on the model.

\subsection{Validity and Reliability}

Before performing structural model analysis, must deal with the issues of validity and reliability. This study also adopted Cronbach's $\alpha$ and confirmatory factor analysis to test the reliability and validity of the questionnaire. When studying basic issues, it would be better for the reliability to be more than 0.70 [41]. The result of the analysis showed that Cronbach's $\alpha$ value of performance expectancy was 0.870 , Cronbach's $\alpha$ value of effort expectancy was 0.937 , and Cronbach's $\alpha$ value of social influence was 0.899 , which indicated that the questionnaire would have quite fine reliability. Since behavioral intention and the actual usage were both single observed variable, the reliability was not included. 
In the confirmatory factor analysis, most potential dimensions took composite reliability value (CR) as the standard. The composite reliability was used to test the internal agreement (similar with Cronbach's $\alpha$ ) of the questions in a questionnaire. High reliability value means high agreement. Then, on the aspect of composite reliability test, Fornell and Larcker [42] suggested the CR value to be higher than 0.60 . The CR value of the performance expectancy was 0.8834 , effort expectancy was 0.9375 and social influence was 0.8913 . From the above mentioned, it showed that the composite reliability were all higher than 0.60 and so the three measuring methods should have a fine reliability [42].

Convergent validity was used to test multiple questions derived from a single variable to see if the result will converge to a single factor. In the confirmatory factor analysis, converge validity of the dimension took the average variance extracted (AVE) as a base. AVE was mainly used to calculate the explanatory power of all observed variable (measuring questions) of the dimension to the average variations. The higher AVE was the higher reliability and converge validity of the dimension was. What comes next was to test the average amount of variance extracted. Reference [43] suggested that AVE should be higher than 0.50 . When a measure method would have good reliability and validity, it would have better internal structure fit. AVE value of performance expectancy was 0.6605 , effort expectancy was 0.7904 , and social influence was 0.6806 (Table 1).

On the aspect of discriminate validity, if a measuring model should have discriminate validity, the correlation level across the potential dimensions should be less than

Table 1. Validity and reliability.

\begin{tabular}{|c|c|c|c|c|c|}
\hline \multicolumn{2}{|c|}{$\begin{array}{c}\text { Observation } \\
\text { Variable }\end{array}$} & \multirow{2}{*}{$\begin{array}{c}\begin{array}{c}\text { Standarized } \\
\text { factor } \\
\text { loadings }\end{array} \\
0.84\end{array}$} & \multirow{2}{*}{$\begin{array}{c}\begin{array}{c}\text { Squared } \\
\text { Multiple } \\
\text { Correlations }\end{array} \\
0.71\end{array}$} & \multirow[t]{2}{*}{$\begin{array}{l}\text { Composite } \\
\text { Reliability }\end{array}$} & \multirow[t]{2}{*}{ AVE } \\
\hline \multirow{4}{*}{$\begin{array}{l}\text { Performance } \\
\text { expectancy } \\
\text { (PE) }\end{array}$} & PE1 & & & & \\
\hline & PE2 & 0.92 & 0.84 & \multirow{3}{*}{0.8834} & \multirow{3}{*}{0.6605} \\
\hline & PE3 & 0.87 & 0.75 & & \\
\hline & PE4 & 0.58 & 0.34 & & \\
\hline \multirow{4}{*}{$\begin{array}{c}\text { Effort } \\
\text { expectancy } \\
\text { (EE) }\end{array}$} & EE1 & 0.80 & 0.63 & \multirow{4}{*}{0.9375} & \multirow{4}{*}{0.7904} \\
\hline & EE2 & 0.85 & 0.73 & & \\
\hline & EE3 & 0.95 & 0.89 & & \\
\hline & EE4 & 0.95 & 0.91 & & \\
\hline \multirow{4}{*}{$\begin{array}{l}\text { Social } \\
\text { influence } \\
\text { (SI) }\end{array}$} & SI1 & 0.97 & 0.94 & \multirow{4}{*}{0.8913} & \multirow{4}{*}{0.6806} \\
\hline & $\mathrm{SI} 2$ & 0.97 & 0.94 & & \\
\hline & $\mathrm{SI} 3$ & 0.66 & 0.43 & & \\
\hline & SI4 & 0.64 & 0.41 & & \\
\hline
\end{tabular}

the correlation level inside the potential dimensions. Therefore, it used the correlation matrix across the dimensions to do the test. The square root of AVE of the potential variables should be greater than the correlation coefficients of other dimensions [44]. The square root of AVE of each dimension was calculated below: AVE value of performance expectancy was 0.6000; The square root of AVE was 0.813. AVE value of effort expectancy was 0.7904 ; The square root of AVE was 0.889 . AVE value of social influence was 0.6806 ; The square root of AVE was 0.825 (Table 2).

The square root values of AVE were all higher than the relevant value in the rows and the columns. This indicated that the performance expectancy, effort expectancy and social influence have discriminate validity.

\subsection{Descriptive Statistics and Inter-Correlations among Research Variable}

The dimension mean scores of the performance expectancy, effort expectancy and the social influence were $3.39,3.48$ and 3.08 respectively which showed their behavioral intention to the e-learning have higher identity with the influential factors of the usage. With standard deviation were $0.62,0.65$ and 0.68 , the informants did not show difference with the perception level, instead the agreement degree was quite high (Table 3). When the behavioral intention mean score fell on 2.86 which was below than the mean score 3, the informants were not passionate to the adoption of the e-learning. On the aspect of the usage, it included those with an e-learning system and those without. The mean score was 1.45 which showed that most of the informants use e-learning system when performing relevant business. The stan-

Table 2. Average variance extracted (AVE).

\begin{tabular}{cccc}
\hline Variable & PE & EE & SI \\
\hline PE & $\mathbf{0 . 8 1 3}$ & & \\
EE & 0.728 & $\mathbf{0 . 8 8 9}$ & \\
SI & 0.595 & 0.590 & $\mathbf{0 . 8 2 5}$ \\
\hline
\end{tabular}

Table 3. Descriptive statistics and inter-correlations among research variable.

\begin{tabular}{cccccccc}
\hline Variables & $\mathrm{M}$ & $\mathrm{SD}$ & 1 & 2 & 3 & 4 & 5 \\
\hline 1. PE & 3.39 & 0.62 & 1 & & & & \\
2. EE & 3.48 & 0.65 & $0.73 * *$ & 1 & & & \\
3. SI & 3.08 & 0.68 & $0.60 * *$ & $0.59 * *$ & 1 & & \\
4. BI & 2.86 & 0.97 & $0.38^{* *}$ & $0.39 * *$ & $0.58^{* *}$ & 1 & \\
5. Usage & 1.45 & 0.50 & 0.11 & $0.16^{*}$ & $0.14 *$ & $0.18^{* *}$ & 1 \\
\hline $\mathrm{N}=264, * \mathrm{p}<0.05, * * \mathrm{p}<0.01, * * * \mathrm{p}<0.001$. & & &
\end{tabular}


dardized deviation was 0.50 .

Except for the performance expectancy, the correlation coefficient of the usage was 0.111 . When any two of them showed no correlative significance, other correlation coefficients showed a relationship between every two dimensions which fell between 0.139 to 0.728 for the with significance $(p<0.05)$. It indicated that the two variables were positively correlated.

To sum up, when informants would have higher awareness level to the coordination facility condition of the performance expectancy, effort expectancy and social influence, they would have higher intention to perform the behavior. Besides, when the awareness level of the performance expectancy, social influence and behavioral intention were higher, the correlation with the usage would be higher as well.

\subsection{Structural Paths and Hypotheses Tests}

On the measuring model of the performance expectancy, effort expectancy, social influence, behavioral intention and usage in this study, the $\chi^{2}$ value of the test result was 2.59 , and when the freedom level was 3 , the significance test probability p-value was 45961 . To see it from other fitness index: GFI $=1.00$, AGFI $=0.98, \mathrm{NFI}=0.99, \mathrm{CFI}$ $=1.00, \mathrm{SRMR}=0.026, \mathrm{RMSEA}=0.00$.

Regarding the exogenous variable and the endogenous variable, only the social influence and behavioral intention showed significance influence (Figure 3). The standardized coefficient value was $0.54(\mathrm{p}<0.001)$ which was more than significant and showed that when the people by the employees reveal their expectation for the employee to access e-learning system, then the employee's behavioral intention would be positively affected. In addition to this, the performance expectancy, effort expectancy and behavioral intention did not show any significance. Accordingly, hypothesis 3 was not rejected.

When two endogenous variables (behavioral intention and usage) would have the direct effect as 0.20 which was higher than significance which showed that the employees' behavioral intention usage caused directive in- fluence. This showed that by lifting the employees' behavioral intention could trigger him/her to perform usage. Accordingly, hypothesis 4 was not rejected. Finally, $\mathrm{R}^{2}$ value of the behavioral intention was $34 \%$ and that of the usage was $1.1 \%$.

\subsection{Results of Moderator Effects}

Basing on prior studies on the variables of the moderator effects, the study was designed to investigate the issue from gender, age and occupation. This approach used a pre-established level of a moderator, which emerges naturally from the study and cannot be modified by researchers. For example, a person's gender, recorded as male or female, naturally forms two moderator levels. To identify a moderation level for age, the dataset was divided to form two sets, each representing individuals who belong to a particular generation. An analysis of age distribution demonstrates that two major age groups emerged: Senior and Journal groups. Representatives of these generations may be fundamentally different in terms of various characteristics, perceptions, and behaviors [45]. Reference [46] used 40 years of age at the day of the survey as a cut-off point. In addition, the classification of the industry is based on Taiwan Common Wealth Magazine which investigated the manufacture business, the service business and the banking business annually.

The moderator effects of user variables were tested by comparing, and the path coefficients produced for each moderator. Path coefficients were calculated using $t$-values suggested by Chow $[45,46]$.

From Table 4 and Figure 4, it could find that gender would cause adjustment to the social influence influenced behavioral intention. Regarding the path coefficient, females have higher social influence influenced behavioral intention $(\beta=0.64 ; \mathrm{p}<0.001)$ than males $(\beta=$ $0.33 ; \mathrm{p}<0.01)$. Gender did not cause any adjustment effect with other paths. Accordingly, Hypothesis 11 was not rejected.

Secondly, on the aspect of age, informants under 40

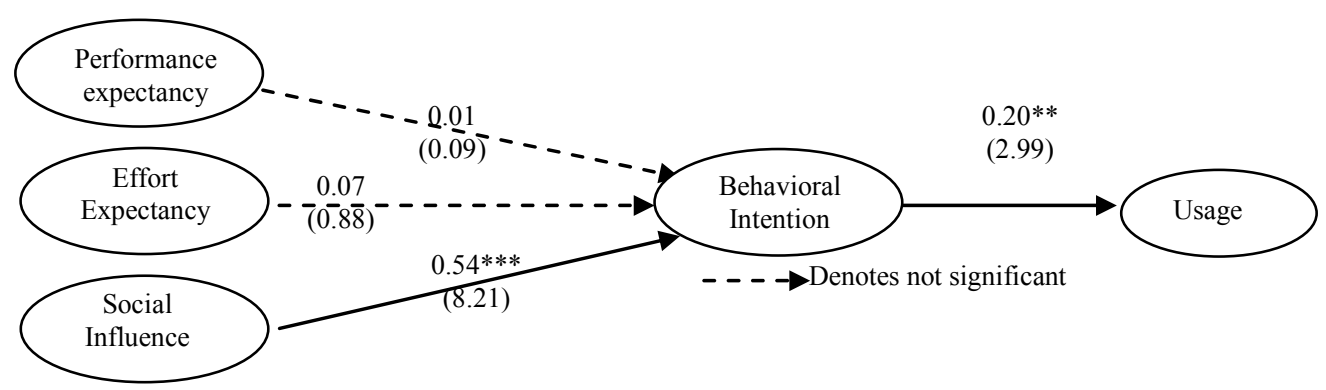

Figure 3. Result of the research model. ${ }^{*} \mathrm{p}<0.05 ;{ }^{* *} \mathrm{p}<0.01 ; * * * \mathrm{p}<0.001$. 
Table 4. The results of moderate effects—gender, age and occupation.

\begin{tabular}{|c|c|c|c|c|c|c|c|}
\hline \multirow{2}{*}{ Path } & \multicolumn{2}{|c|}{ Gender } & \multicolumn{2}{|c|}{ Age } & \multicolumn{3}{|c|}{ Occupation } \\
\hline & Male & Female & Senior & Junior & Manufacturing & Service & Bank \\
\hline $\mathrm{PE} \rightarrow \mathrm{BI}$ & 0.26 & -0.12 & -0.07 & 0.23 & 0.11 & 0.02 & -0.27 \\
\hline $\mathrm{EE} \rightarrow \mathrm{BI}$ & 0.06 & 0.06 & 0.05 & 0.23 & 0.07 & -0.07 & 0.29 \\
\hline $\mathrm{SI} \rightarrow \mathrm{BI}$ & $0.33 * *$ & $0.64 * * *$ & $0.63 * * *$ & 0.18 & $0.50 * * *$ & $0.58 * * *$ & $0.46^{*}$ \\
\hline
\end{tabular}

$\mathrm{N}=264,{ }^{*} \mathrm{p}<0.05, * * \mathrm{p}<0.01,{ }^{* * *} \mathrm{p}<0.001$.

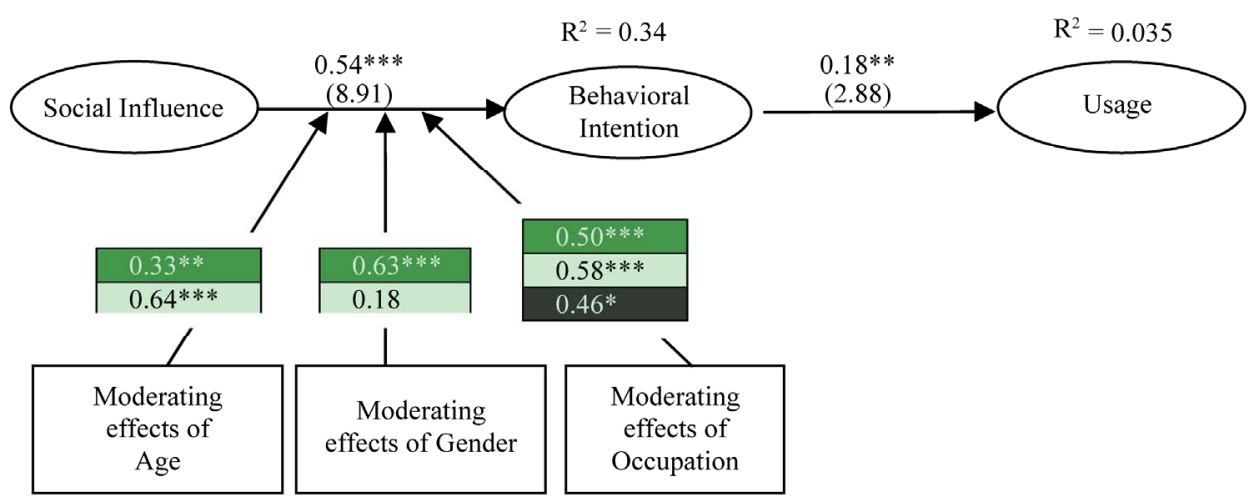

Figure 4. Results of moderator effects. *p $<0.05 ; * * \mathbf{p}<0.01 ; * * * \mathbf{p}<0.001$

years old show that their social influence would affect the behavioral intention significantly $(\beta=0.63 ; \mathrm{p}<$ 0.001). Accordingly, hypothesis 9 was rejected.

Besides, from the perspective of occupation, manufacture business, service business and banking business all showed significant adjustment effect regarding social influence influenced behavioral intention. Among all, the service business $(\beta=0.58 ; \mathrm{p}<0.001)$ would have the highest strength, then the manufacture business $(\beta=0.50$; $\mathrm{p}<0.001)$ and the banking business $(\beta=0.46 ; \mathrm{p}<0.05)$. Accordingly, hypothesis 13 was not rejected.

Hypothesized results are as Table 5.

\section{Discussion and Conclusions}

\subsection{Discussion}

Several hypotheses can be drawn from this study.

1) In the model assumed, only social influence influenced behavioral intention and usage would cause positive significance. The influence of the performance expectancy and effort expectancy influence behavioral intention would not cause positive significance. Therefore, the adoption of UTAUT model in this study was only partial applicable.

2) UTAUT model was proposed by Venkatesh et al. [5] explain $70 \%$ of the behavioral intention. But it was only explained $34 \%$ of the behavioral intention in this study which adopted UTAUT model. The difference between the two explanatory results might be due to the reasons listed below:

a) The employees or managers of the three major oc- cupations in Taiwan did not think mobile learning would help their working performance and thus it was not a factor to affect their behavioral intention.

b) The employees or managers of the three major occupations in Taiwan are not because the devices are easy-to-use and to use them.

c) The employees of the three major occupations would use mobile instrument to access the e-learning for the users think that their significant other may think that he/she should use the new system. The motivation was not hard to understand. In Taiwan, if an employee wanted to advance his/her job training; he/she would only need to pay partial of the fee. Council of Labor affairs of Republic of Taiwan would support $80 \%$ of the credit fees. Employees older than 45 years old can even get full support from the government. The up-limit of the support was around 950 USD within three years. Therefore, behavioral intention to use the technologies was mostly external factors, instead of self-triggered motivation. From Lee and Huang [46] indicated because of the "external expectation", the "social relationship" and the "working behaviors" that push the employees to use the mobile learning system.

d) Since UTAUT model established by Venlatesh et al. [5] was a model established for the acceptance of the new information technology by the businessmen and there were some cognitive of latent construct difference between Eastern and Western cultures, it might also result in the explanatory power of the behavioral intention and usage is lower. 
Table 5. Hypothesized results.

\begin{tabular}{ccc}
\hline H3 & Social influence has a positive effect on behavioral intention to use m-learning. & not rejected \\
H4 & Behavioral intention has a significant positive influence on usage. & not rejected \\
H11 & Social influence influences behavioral intention to use m-learning more strongly for women than for men. & not rejected \\
H13 & Social influence influences behavioral intention to use m-learning relationship would be the impact of dif- & not rejected \\
\hline
\end{tabular}

3) It found in this study that gender and age would cause significant inference to the derivation of the path of social influence influenced behavioral intention. This agreed with the suggestion by Venlatesh et al. [5]. Meanwhile, it was also observed that different business would have significant inference to the path of the social influence influenced behavioral intention which matches with researches on different occupations (e.g., [1,37,38]).

4) On the aspect of moderator variables, it observed that social influence influenced behavioral intention to use m-learning more strongly for women than for men. This finding could relate with general findings that women were generally more empathic than were men [47-49], women sought out and received more emotional social support and overall support than men, and women were more likely than men to seek support, received needed support, and would have higher perceptions of social support [50-52].

5) On the aspect of moderator variables, it also found that employees under forty years old would have stronger social influence influenced behavioral intention than those over forty years old. It was something worth of attention. Though Venlatesh et al. [5] mentioned in the literature that elders would be easier to be influenced by social influence than the youth, as now the unemployment rate has broken the records and many jobs was provided with relationship-oriented factor, the youth in Taiwan would gradually emphasize on the social influence. That is to say, the youth would observe the needs of the interested people. Furthermore, since there were $73 \%$ of the employments between 15 years old to 24 years old were in the service business, it was critical to enhance the quality of the business service and competitiveness.

6) On the aspect of moderator variables, it found that among all the business, employees of the service business were more easily affected by social influence than the employees of manufacture or banking business. It was obvious that each business would have its own unique resource perception on the social influence. According to Taiwan government survey, the GPD ratio of service business in Taiwan was $73.2 \%$, the employment number of the service business was 6 million and 40 thousand which takes $58 \%$ of the overall employment number. Plus the environmental influence in Taiwan, all of these may be the reason why service business was much easier affected by behavioral intention than other business.

\subsection{Conclusions}

The result of the research indicates that social influence would have a positive effect on behavioral intention to use m-learning. That means when the employees in the three major occupations in Taiwan are using mobile device to access mobile learning, the more their significant others (i.e., colleagues, superior manager or friends) thought that they should use the mobile device, the more they would have behavioral intention to use one. Therefore, when the director of managers department or HR department are introducing mobile device for mobile learning, they shell pay attention to the situation of the usage of the mobile device. When the behavioral intention is low, they can suggest their colleagues, superior manager or friends to communicate with them to enhance their intention and to use it.

From the analysis of the moderator variable of the research, it can found that gender was an important moderator. The paths of each social influence influenced behavioral intention significantly interfered where the path relation was stronger among young females. This showed that when a mobile device was introduced for mobile learning, the perception of the social influence would cause higher intention for young females than males. Therefore, when a corporation is trying to introduce a mobile device to perform mobile learning, it suggests that male employees and elder employees shell is put more emphasis on the communication to enhance their behavioral intention.

\subsection{Study Limitations and Future Directions}

There were three limitations in this study. The first limitation concerned the explanatory power of the models. Most of the existing studies account for less than $60 \%$ of variance explained, especially those using field studies with professional users [7]. Therefore, when UTAUT model was used in different countries, the model should be adjusted to fit the conditions of each country.

Regarding the timing of the research, this study took single-time approach which was different from the 
UTAUT model which was proposed by Venkatesh et al. [5] where three measuring time of the same groups of samples should be applied. This may also be the reason that causes the result is different.

Since the result of the research indicated that the users of the three major occupations in Taiwan was mostly motivated by social influence, it suggests that future study can focus on the application relation between the social influence and the users' behavioral intention for new technologies.

\section{Acknowledgements}

The authors would like to thank Taiwan Institute for Information Industry provides the information.

\section{REFERENCES}

[1] T. Zhou, Y. B. Lu and B. Wang, "Integrating TTF and UTAUT to Explain Mobile Banking User Adoption," Computers in Human Behavior, Vol. 26, No. 4, 2010, pp. 760-767. doi:10.1016/j.chb.2010.01.013

[2] P. Y. K. Chau and P. J. H. Hu, "Investigating Healthcare Professionals' Decisions to Accept Telemedicine Technology: An Empirical Test of Competing Theories," Information \& Management, Vol. 39, No. 4, 2002, pp. 297311. doi:10.1016/S0378-7206(01)00098-2

[3] Taiwan Institute for Information Industry, "The Investigation of Corporate E-Learning into the Status-Results Report (100 Largest Financial)," National E-Learning Network Science Park Plans to Shape Science and Technology, 2005.

[4] Industrial Development Bureau, Ministry of Economic Affairs in Taiwan, "The Ratios among the Occupations of Manufacture, Banking and Service in Buying or Making E-Learning Platform," 2010. http://www.moeaidb. gov.tw/

[5] V. Venkatesh, M. Morris, G. B. Davis and F. D. Davis, "User Acceptance of Information Technology: Toward a Unified View," MIS Quarterly, Vol. 27, No. 3, 2003, pp. 425-478.

[6] W. W. Chin, B. L. Marcolin and P. R. Newsted, "A Partial Least Squares Latent Variable Modeling Approach for Measuring Interaction Effects: Results from a Monte Carlo Simulation Study and an Electronic-Mail Emotion/Adoption Study," Information Systems Research, Vol. 14, No. 2, 2003, pp. 189-217. doi:10.1287/isre.14.2.189.16018

[7] H. Sun and P. Zhang, "The Role of Model Rating Factors in User Technology Acceptance," International Journal Human-Computer Studies, Vol. 64, No. 2, 2006, pp. 5378. doi:10.1016/j.ijhcs.2005.04.013

[8] F. D. Davis, "Perceived Usefulness, Perceived Ease of Use, and User Acceptance of Information Technology," MIS Quarterly, Vol. 13, No. 3, 1989, pp. 319-334. doi: $10.2307 / 249008$

[9] R. Agarwal and J. Prasad, “Are Individual Differences
Germane to the Acceptance of New Information Technologies?" Decision Sciences, Vol. 30, No. 2, 1999, pp. 361-391. doi:10.1111/j.1540-5915.1999.tb01614.x

[10] S. Kulviwat, G. C. Bruner II, A. Kumar, S. A. Nasco and T. Clark, "Toward a Unified Theory of Consumer Acceptance Technology," Psychology and Marketing, Vol. 24, No. 12, 2007, pp. 1059-1084. doi:10.1002/mar.20196

[11] S. Taylor and P. A. Todd, "Understanding Information Technology Usage: A Test of Competing Models," Information Systems Research, Vol. 6, No. 2, 1995, pp. 144-174. doi:10.1287/isre.6.2.144

[12] V. Venkatesh and M. Morris, "Why Don’t Men Ever Stop to Ask for Directions? Gender, Social Influence, and Their Role in Technology Acceptance and Usage Behavior," MIS Quarterly, Vol. 24, No. 1, 2000, pp. 115-139. doi:10.2307/3250981

[13] V. Venkatesh, "Veterminants of Perceived Ease of Use: Integrating Control, Intrinsic Motivation, and Emotion into the Technology Acceptance Model," Information Systems Research, Vol. 4, No. 4, 2000, pp. 342-365. doi:10.1287/isre.11.4.342.11872

[14] D. Y. Kim, J. Park and A. M. Morrison, "A Model of Traveller Acceptance of Mobile Technology," International Journal of Tourism Research, Vol. 10, No. 5, 2008, pp. 393-407. doi:10.1002/jtr.669

[15] R. Agarwal and J. Prasad, "A Conceptual and Operational Definition of Personal Innovativeness in the Domain of Information Technology," Information Systems Research, Vol. 9, No. 2, 1998, pp. 204-215. doi:10.1287/isre.9.2.204

[16] I. Ajzen and M. Fishbein, "Understanding Attitudes and Predicting Social Behavior," Englewood Cliffs, Prentice-Hall, Upper Saddle River, 1980.

[17] M. Fishbein and I. Ajzen, "Belief, Attitude, Intention, and Behavior: An Introduction to Theory and Research," Addison-Wesley, Reading, 1975.

[18] I. Ajzen, "From Intentions to Actions: A Theory of Planned Behavior," In: J. Kuhl and E. Beckmann, Eds., In Action Control: From cognition to Behavior, SpringerVerlag, Berlin, 1985, pp. 11-39.

[19] G. C. Moore and I. Benbasat, "Development of an Instrument to Measure the Perceptions of Adopting an Information Technology Innovation," Information Systems Research, Vol. 2, No. 3, 1991, pp. 192-222. doi:10.1287/isre.2.3.192

[20] F. D. Davis and V. Venkatesh, "A Critical Assessment of Potential Measurement Biases in the Technology Acceptance Model: Three Experiments," Internet Journal of Human-Computer Studies, Vol. 45, No. 1, 1996, pp. 1945.

[21] V. Venkatesh and F. D. Davis, "A Theoretical Extension of the Technology Acceptance Model: Four Longitudinal Field Studies," Management Science, Vol. 46, No. 2, 2000, pp. 186-204. doi:10.1287/mnsc.46.2.186.11926

[22] F. D. Davis, R. P. Bagozzi and P. R. Warshaw, "User Acceptance of Computer Technology: A Comparison of 
Two Theoretical Models," Management Science, Vol. 35, No. 8, 1989, pp. 982-1003. doi:10.1287/mnsc.35.8.982

[23] R. L. Thompson, C. A. Higgins and J. M. Howell, "Personal Computing: Toward a Conceptual Model of Utilization," MIS Quarterly, Vol. 15, No. 1, 1991, pp. 125143. doi: $10.2307 / 249443$

[24] F. D. Davis, R. P. Bagozzi and P. R. Warshaw, "Extrinsic and Intrinsic Motivation to Use Computers in the Workplace," Journal of Applied Social Psychology, Vol. 22, No. 14, 1992, pp. 1111-1132. doi:10.1111/j.1559-1816.1992.tb00945.x

[25] D. R. Compeau and C. A. Higgins, "Computer Self-Efficacy: Development of a Measure and Initial Test," MIS Quarterly, Vol. 19, No. 2, 1995, pp. 189-211. doi: $10.2307 / 249688$

[26] D. R. Compeau, C. A. Higgins and S. Huff, "Social Cognitive Theory and Individual Reactions to Computing Technology: A Longitudinal Study," MIS Quarterly, Vol. 23, No. 2, 1999, pp. 145-158. doi:10.2307/249749

[27] M. Ahearne, N. Srinivasan and L. Weinstein, "Effect of Technology on Sales Performance: Progressing from Technology Acceptance to Technology Usage and Consequence," Journal of Personal Selling \& Sales Management, Vol. 24, No. 5, 2004, pp. 297-310.

[28] I. Ajzen, "The Theory of Planned Behavior," Organizational Behavior and Human Decision, Vol. 50, No. 2, 1991, pp. 179-211. doi:10.1016/0749-5978(91)90020-T

[29] Y. S. Wang, M. C. Wu and H. Y. Wang, "Investigating the Determinants and Age and Gender Differences in the Acceptance of Mobile Learning," British Journal of Educational Technology, Vol. 40, No. 1, 2009, pp. 92-118. doi:10.1111/j.1467-8535.2007.00809.x

[30] S. Taylor and P. A. Todd, "Assessing IT Usage: The Role of Prior Experience," MIS Quarterly, Vol. 19, No. 2, 1995, pp. 561-570. doi:10.2307/249633

[31] H. C. Triandis, "Interpersonal Behavior," Brooke/Cole, Monterey, 1977.

[32] E. M. Rogers, "Diffusion of Innovations," 5th Edition, Free Press, New York, 2003.

[33] A. Bandura, "Social Foundations of Thought and Action: A Social Cognitive Theory," Prentice Hall, Englewood Cliffs, Upper Saddle River, 1986.

[34] E. M. Rogers, "Diffusion of Innovations," Free Press, New York, 1995.

[35] I. Ajzen and M. Fishbein, "Attitude-Behavior Relations: A Theoretical Analysis and Review of Empirical Research," Psychological Bulletin, 1977, pp. 84-85.

[36] T. Koivumäki, A. Ristola and M. Kesti, "The Perceptions Towards Mobile Services: An Empirical Analysis of the Role of Use Facilitators," Personal and Ubiquitous Computing, Vol. 12, No. 1, 2008, pp. 67-75.

[37] F. C. Tung, M. S. Lee, C. C. Chen and Y. S. Hsu, "An Extension of Financial Cost and TAM Model with IDT for Exploring Users' Behavioral Intentions to Use the CRM Information System," Social Behavior and Per- sonality, Vol. 37, No. 5, 2009, pp. 621-626. doi:10.2224/sbp.2009.37.5.621

[38] Y. C. Lee, M. L. Li, T. M. Yen and T. H. Hua, "Analysis of Adopting an Integrated Decision Making Trial and Evaluation Laboratory on a Technology Acceptance Model," Expert System with Application, Vol. 37, No. 2, 2010, pp. 1745-1754. doi:10.1016/j.eswa.2009.07.034

[39] V. Venkatesh, M. G. Morris and P. L. Ackerman, "A Longitudinal Field Investigation of Gender Differences in Individual Technology Adoption Decision Making Processes," Organizational Behavior and Human Decision Processes, Vol. 83, No. 1, 2000, pp. 33-60. doi:10.1006/obhd.2000.2896

[40] T. K. Peng, Y. T. Kao and C. C. Lin, "Common Method Variance in Management Research: Its Nature, Effects, Detection, and Remedies," Journal of Management, Vol 23, No. 1, 2006, pp. 77-98.

[41] J. C. Nunnally, "Psychometric Theory," 2nd Edition, McGraw-Hill, New York, 1978.

[42] C. Fornell and D. F. Larcker, "Evaluating Structural Equation Models with Unobservable Variables and Measurement Error," Journal of Marketing Research, Vol. 18, No. 1, 1981, pp. 39-50. doi:10.2307/3151312

[43] R. P. Baggozzi and Y. Yi, "On the Evaluation of Structural Equation Models," Academic of Marketing Science, Vol. 16, No. 1, 1988, pp. 76-94.

[44] J. F. Jr. Hair, R. E. Anderson, R. L. Tatham and W. C. Black, "Multivariate Data Analysis," 5th Edition, Prentice Hall, Upper Saddle River, 1998.

[45] D. H. Shin, "Towards an Understanding of the Consumer Acceptance of Mobile Wallet," Computers in Human Behavior, Vol. 25, No. 6, 2009, pp. 1343-1354. doi:10.1016/j.chb.2009.06.001

[46] G. C. Chow, "Tests of Equality Between Sets of Coefficients in Two Linear Regressions," Econometrica, Vol. 28, No. 3, 1960, pp. 591-605. doi:10.2307/1910133

[47] K. Serenko, O. Turel and S. Yol, "Modelrating Roles of User Demographics in the American Customer Satisfaction Model within the Context of Mobile Services," Journal of Information Technology Management, Vol. 17, No. 4, 2006, pp. 20-32.

[48] T. Z. Lee and L. Y. Huang, "Related Research in Learning Motivation, Learning Satisfaction and Learning Performance of Continuing Education for In-service Personage: Taking in-Service Master Program of NCKU as Example," Journal of Human Resource Management, Vol. 7, No. 4, 2007, pp. 1-24.

[49] A. Macaskill, J. Maltby and L. Day, "Forgiveness of Self and Others and Emotional Empathy," The Journal of Social Psychology, Vol. 142, No. 5, 2002, pp. 663-665. doi:10.1080/00224540209603925

[50] B. A. Gault and J. Sabini, "The Roles of Empathy, Anger, and Gender in Predicting Attitudes Toward Punitive, Reparative, and Preventative Public Policies," Cognition and Emotion, Vol. 14, No. 4, 2000, pp. 495-520. doi:10.1080/026999300402772 
[51] K. C. McLeland and G. W. Sutton, "Sexual Orientation, Mental Health, Gender, and Spirituality: Prejudicial Attitudes and Social Influence in Faith Communities," Journal of Psychology and Theology, Vol. 36, No. 2, 2008, pp. 104-113.
[52] L. E. McClelland and J. A. McCubbin, "Social Influence and Pain Response in Women and Men," Journal of Behavioral Medicine, Vol. 35, No. 1, 2008, pp. 413-420. doi:10.1007/s10865-008-9163-6 